\title{
ESSAY
}

Invited article

DOI: http://dx.doi.org/10.1590/S0034-759020170309

\section{DYNAMIC CAPABILITIES: FOSTERING AN INNOVATION-FRIENDLY ENVIRONMENT IN BRAZIL}

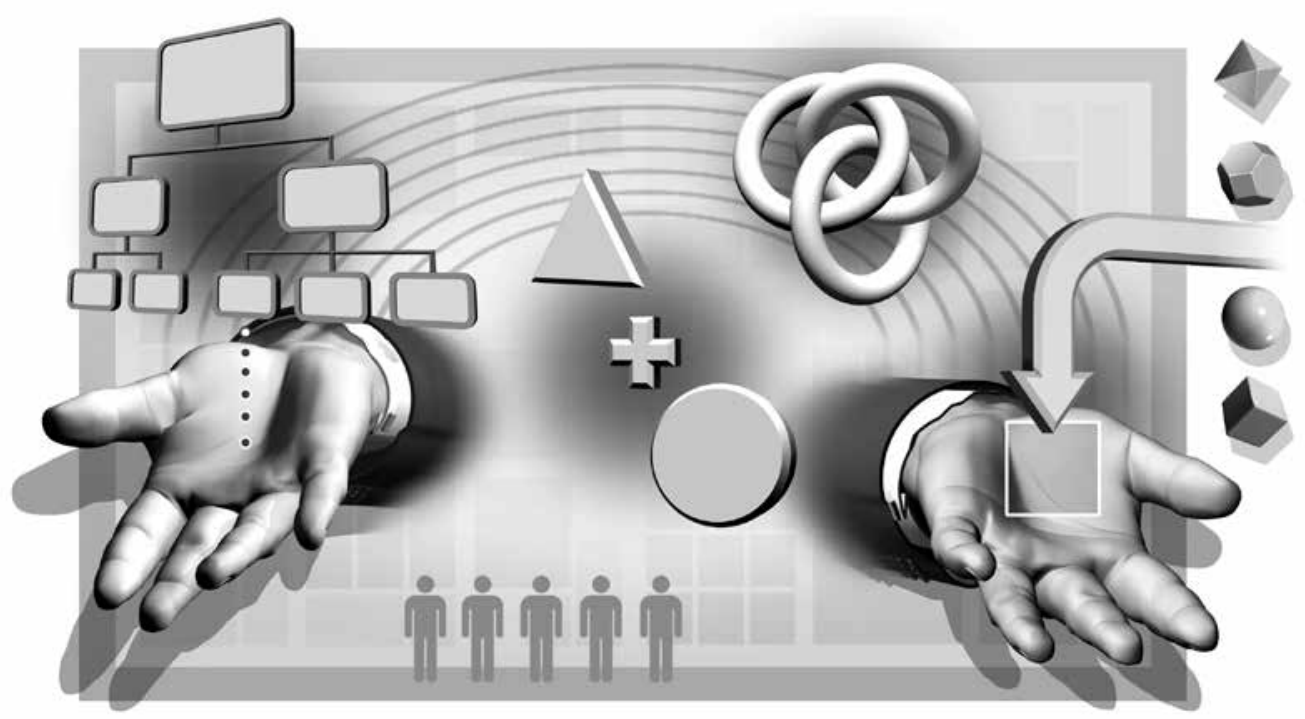

\section{INTRODUCTION}

Even though twenty years have elapsed since the publication of the paper Dynamic Capabilities and Strategic Management (Teece, Pisano \& Shuen, 1997), many scholars and some executives maintain their interest in this framework so as to better understand how firms develop, maintain competitive advantage, and sustain superior enterprise performance. Individual firm performance depends not only on the markets in which firms compete and the environments in which they are

JÚLIA DOEBBER HERRMANN juliadherrmann@gmail.com International Executive Director at the First Silicon Valley Institute for Business Innovation Un-conference - California, USA

\section{LUCAS CÉ SANGALLI}

lucas.sangalli@gmail.com Executive Producer at the First Silicon Valley Institute for Business Innovation Un-conference - California, USA

\section{DAVID J. TEECE}

teece@haas.berkeley.edu

Co-founder of the Silicon Valley Institute for Business Innovation - California, USA embedded, but also on managerial acumen.

In 2002, the 1997 Dynamic Capabilities and Strategic Management paper earned the Strategic Management Society's Best Paper Award. In 2005, it was deemed the most cited paper worldwide in the Science Watch index of Scientific Research in Economics and Business for the period 1995-2005. The paper currently has over 28,000 Google Scholar cites. Additionally, the dynamic capabilities concept was recognized in 2009 with an award from the Emerald Literati Network.

One of the possible reasons why the dynamic capabilities concept has received attention is that it is grounded in the activities of the lead author. The key insights in the dynamic capabilities framework flow from Teece's experience in building, financing, and running sizeable companies, as well as his knowledge and insight as an active scholar. We are taught in economics that resource allocation is done by markets; however, inside a firm, resource allocation is done by managers. More importantly, the astute internal allocation of resources is just as important as the role of markets in allocating investment to higher yield opportunities. Put differently, proficiency in the allocation of 
resources inside firms is as important as that between firms by the capital markets.

The key difference between the two types of allocations is that the resources and assets that managers allocate are unpriced because they are intangible (or, otherwise specialized) and are rarely bought or sold. When markets are thin and/or transactions are non-existent, they do not work well. Managers then have to allocate resources using what historian Alfred Chandler (1990) called the "visible hand." The economic system simply cannot rely on Adam Smith's “invisible hand" in a non-existent market. These considerations help explain the insights that the dynamic capabilities framework has provided through the decades.

It is broadly recognized nowadays that managers not only manage downwards through hierarchies, but also have to manage partnerships, alliances, and external communities. This is how they energize business ecosystems. The dynamic capabilities framework highlights both these internal and external roles of managers. The performance of a firm and its management depends on how effectively the top management avails of and employs the resources it owns and has access to. This insight helps explain why scholars have found the dynamic capabilities framework useful. It very clearly defines the distinct role of managers in the economy. The framework brings both the firm's internal as well as external perspectives together in a coherent manner. It also helps regulators and government officials better understand the distinctive role of the modern business enterprise.

Being aware of developments in the environment within which a firm competes is part of a manager's responsibilities. Another component of strong dynamic capabilities involves recognizing that one should also be able to shape the environment. This is the point where textbook economics should be set aside, because textbooks assume that the market environment is a given, and not subject to impact by any individual firm. This assumption is particularly true in the models of perfect competition - where companies are one amongst many - and they do not really impact anything. Such models are quite unhelpful for much of the time.

Managers should be aware that they can often shape the business environment to their advantage. Firms can shape the environment not just through innovation, but also through social and political action. If an environment is not conducive to a business, one can contemplate how one can shape attitudes and government action through communication and information. This element adds a truly interesting dimension. It takes into consideration the idea that managers can benefit from the unknown, which is of particular interest in situations where outcomes are not easily predictable and uncertainty is widespread. This notion becomes even more interesting if we apply it to environments such as the United States under Trump's presidency and post-impeachment Brazil.

\section{ACTING IN A DEEPLY UNCERTAIN ENVIRONMENT}

Today's world is one where mere risk is not a grave problem anymore. Risk is something that can be managed. With known risks, managers know the probability with which certain things are going to happen, even though they cannot be predicted exactly. On the other hand, no one can ascertain how to manage uncertainty, i.e., when the unknown is unknown. Events such as the Trump election, Brexit, post-impeachment Brazil, and so on, have elements of deep uncertainty, which is the enemy of investment.

The dynamic capabilities framework is especially pertinent to regimes of rapid technological change. Such regimes create the condition of deep uncertainty. With the advent of technological change, one does not know what is going to happen next. Sur- prises abound everywhere and they can be both pleasant as well as unpleasant. Any circumstance characterized by deep uncertainty is one where strong dynamic capabilities are needed. Such uncertainty may be the result of innovation, political developments, and financial disturbances.

Therefore, it is clear that dynamic capabilities are relevant wherever surprises occur. It is very difficult to gauge precisely how a globally connected economic system functions: even the people running it are not quite sure. In this context, the world has a greater need for dynamic capabilities because that is the way forward. One can never predict what is coming next, but if one can sense and prepare for it a little ahead of the competition, and then react to it quickly, adapt, and move on, one can be advantageously positioned.

Although uncertainty may be bad for investments, some managers seem able to find a way around it. John Maynard Keynes attributed this to what he called "animal spirits." Business people have to make decisions even in the midst of dire amounts of uncertainty because they must act - they cannot sit around waiting for perfect clarity of circumstance or outcome. To act wisely and adroitly in a deeply uncertain environment is a dynamic capability, as is the ability to "see around corners" using tools such as big data, having insights, being in the right networks, and having a good sense of how things hang together (Teece, Peteraf \& Leih, 2016).

However, whence do we obtain dynamic capabilities? Are they a characteristic of a firm? Is the manager of a firm somehow attached to it in the long term? Do these capabilities reside in the management team or do they reside deeper within the organization?

\section{WHERE DO DYNAMIC CAPABILITIES RESIDE?}

Dynamic capabilities lie partly with the firm and partly with the management team. One 
of the key factors often overlooked is that in the governance of a firm, the board of directors chooses the management. Furthermore, sometimes the board does not make the best choice. Having a board of directors able to identify proficient individuals who are able to deliver good outcomes is a governance function and, as such, it is essentially a dynamic capability as well.

Governance is something that is integral to a firm because typically the tenure of the board of directors is longer than the tenure of managers. Boards need to help assemble the right management team. However, a good leader may not remain with the firm forever. Hopefully, if the organization is aware of what is needed, and places a priority on sensing, seizing, and transforming, the board will then select other managers who meet those criteria and will sustain the firm's dynamic capabilities beyond the tenure of an individual manager (Augier \& Teece, 2009).

This was one of the questions that arose when Steve Jobs passed away. People everywhere where asking whether that was the end of Apple. It could have been, but it was not. If the succession plan was good and if Job's beliefs were embedded in Apple's organizational culture, then the firm could continue to have a durable, superior performance. This involves ensuring that the firm has the right people on the management team, which requires training that is not necessarily classroom training. Bringing along, encouraging, and mentoring people in the "Apple way" of doing things are part of what is required.

Part of the responsibility of a leader is the ability to instill an entrepreneurial culture in the management team that goes beyond their own tenure. Good managers nurture people so they have strong sensing, seizing, and transforming aptitudes. An organization has no chance without entrepreneurial leaders who sustain the role of a "bricolage," i.e., encapsulate elements of entrepreneur, leader, and manager. If a firm finds a leader that can motivate and guide the other people in the management team, there is a good chance that it will develop strong dynamic capabilities. If the CEO does not share that vision, the firm's capabilities are unlikely to be dynamic. That is not to say that all the capabilities lie with the CEO or the top management team, but it is impossible for other people to work around the CEO and the top management team if they are not onboard for building and exercising dynamic capabilities.

We can illustrate this with three examples. Jeff Bezo's Amazon went from selling books online to cloud computing. Amazon is a firm with a constant willingness to experiment and to build to scale, with sensitivity to the broader environment. Consistent with dynamic capabilities, it is a pioneering firm that does not pay attention to short-term profitability. Strong dynamic capabilities are often more evident in new firms rather than in old ones. Occasionally older firms will have periods when they become very dynamically capable, such as in the case of IBM, GKN, Enel, and Santa Casa de Misericórdia de Porto Alegre.

In large organizations, outside investors are often constraints when they force the firm to focus on short-term profits. Activist shareholders of publicly traded companies with a focus on near-term profits often pressure boards of directors to change the management team in order to increase (short-term) earnings per share. Investments for the long term are often sacrificed to achieve these results. This problem is serious in markets where traders outnumber shareholders. In the United States, the "hold period" for shares on the major stock exchanges has reduced from years to weeks. When capital markets are dominated by a "trading" rather than a "holding" mentality, the growth and long-term development of listed business enterprises are compromised. Achieving strong dynamic capabilities can thus invite a battle with investors (Teece, 2010). Without a supportive investor base and governance system fo- cused on the long run, it is almost impossible for firms to exhibit strong dynamic capabilities.

Dynamic capabilities can also be present in family businesses. In such businesses, accountability is generally restricted to the family members. This is an advantage if the family is supportive of adopting a longterm view, but can present a challenge if it is not united and does not share a common vision of long-term growth and development. Since families are not traders, it is easier for them to support the management teams for the longer term. Even though families might have multigenerational issues, they are well positioned to select managers who can sense, seize, and transform in order to avoid becoming obsolete and losing not only money, but also identity and reputation.

Thus, the underpinnings of dynamic capabilities are present in family firms; however, this does not guarantee that they will, in fact, emerge. It demands an understanding by the family of what is needed. The right managers need to be selected from the family or elsewhere. It also involves supporting the managers at the board level and guiding them toward the kind of managerial style and long-term perspective that is required by dynamic capabilities. Older generations of the family may also rely on their financial position to support the younger generations in their endeavors, making sure that their investments are also diversified.

Sometimes younger people can think "out of the box" more readily; this is partly because they do not always know where the box is. That works well for startups and it is not surprising that many young people are succeeding at startups. It is necessary to make it clear, though, that for dynamic capabilities you also have to succeed in organizations that are much larger than small startups and that is where young people have to learn. Managing a large organization has a lot more complexity attached to it, and there is a need to be very persuasive and influential beyond the half dozen people that may 
be part of a startup team. That is where leadership comes in. Younger entrepreneurs have an advantage in the startup environment because they are not constrained by the habits of the past. However, if and when the company gets bigger, the younger generation's learning needs to keep pace with the company's growth. If they succeed in that, they can stay in a leadership role for a long time, as can be seen in the case of Sergey Brin and Larry Page at Google.

Accordingly, it is important to recognize that there is also a different set of skills that is needed when an organization becomes bigger, which calls for larger organizations to put in place a certain amount of structure. Google founders Page and Brin brought in Eric Schmidt as CEO to run the company in order to enable the two founders to build the organization. Schmidt was an experienced CEO. As the young found ers recognized and articulated, they needed "adult supervision" to run the company.

With that in mind, we can say that young people's skills are great for startups, but not all of them seem able to learn how to operate in a large company environment. Eventually, if the company is successful, they will need to learn or otherwise hand over control to someone else. Boards of directors and markets were once skeptical about founders transitioning from a startup to a large company. Evidence such as the F-shares (non-voting founder shares) issued by Google and Facebook show that this attitude is changing. The market does not significantly discount non-voting shares anymore. Investors are figuring out that sometimes they are better off having the founders in control.

\section{DYNAMIC CAPABILITIES AND THE BUSINESS ECOSYSTEM}

Regarding the development of strong dynamic capabilities, it appears that it does not matter if it is a family business, a startup, or a tech giant; it all comes down to the ability of management to astutely build, select, and orchestrate assets, using the sense, seize, and transform mantra. If innovation is an unfinished process, so are dynamic capabilities.

If a region or a nation does not have an entrepreneurial culture, it is hard to have an effective entrepreneurial management team. The absence of an entrepreneurial climate in a region constrains the development of dynamic capabilities.

Industrial policy experts often fail to appreciate that what is distinctive in Silicon Valley firms is that their management and the entrepreneurial aspects do require dynamic capabilities. If a company does not have dynamic capabilities, it will not exist for very long. It is not just a state of mind, but rather a set of organizational structures and business practices, coupled with a certain way of prioritizing that is important. Dynamic capabilities require that companies stay entrepreneurial as they scale, constantly scanning the periphery of their ecosystems and their marketplaces to identify emerging threats and opportunities. This requires knowledge that it is actually difficult to acquire; one cannot "Google it" and find the information one needs. One needs to be in dense networks to figure out the next big thing. Bits and pieces of the required information are scattered about in the minds of brilliant people in the Silicon Valley and everywhere, including in the minds of lead customers. Even though the Silicon Valley is a technological hub, it is also a place with an abundance of customers. People come to the Silicon Valley because they also want new things; it is not only a place to create new things, but also to discover new things. However, unless one then has the capabilities and the organizational backing to execute well, one will not go very far.

The unique thing about the Silicon Valley is that it has become the nursery for the world's great new globally scalable companies, e.g., Apple, Google, Oracle, Intel, Face- book, Genentech, and many more. There are a lot of places that create new companies, but what is unique about the Silicon Valley is that it tends to routinely create global scalable companies, i.e., companies that go on to comprise more than just half dozen talented people, as wonderful as that is. The Silicon Valley incubates and nurtures large enterprises that satisfy the needs of consumers all over the world while simultaneously creating jobs and shareholders' wealth.

What make the Silicon Valley special are the supporting institutions, great universities, corporate research labs, government research labs, venture capital, and startup companies (e.g., the Cambridge Cluster around Cambridge University in the United Kingdom) themselves (Somaya, Teece \& Wakeman, 2011). To replicate the Silicon Valley, one must understand the whole panoply of institutions and enterprises, the people, the way they think, and what motivates them. The Silicon Valley culture has a sense of urgency and a deep passion for getting things done, making a difference, creating a new business and, as Steve Jobs put it in a speech at the Stanford University, "making a small dent in the universe."

The Silicon Valley is about building bridges and creating connections. An understanding between managers and academics must also be fostered. There is a lot of wisdom in the academic literature, and academics are aware of that. There is almost a requirement that social science research in economics and business be presented to practitioners in a way that is meaningful to them because having research findings available but ignored is a tragedy. A lot of managers do not read very much and keep reinventing the wheel at great cost to themselves and their stakeholders. They have to learn things from first principles, and learn things the hard way, but there are easier ways. Therefore, the question "why does the gap between academics and managers not get closed" remains unresolved. 
We might suggest that there is both a communication and a translation gap. Academics need to learn how to convey their ideas simply and understand the context in which research-based knowledge is applicable. This requires more than just understanding the research; it also requires wisdom to know how the research relates to other research and practices. Academics need to be broadly read and exposed to practices; there are no silver bullets. One also needs deep and broad networks to be effective. If someone comes up with just one little snippet of research or of information, or just a little idea, and hopes to help managers, the chances of success are low. Once the problem is understood, one can be well equipped to assist companies and their management. More of that will happen in places like Brazil once there is recognition in the corporate world that, in fact, some academics have the capacity to translate ideas into action.

If entrepreneurs want to create a global scalable company or be better at managing, they need to have connections everywhere, not only in the corporate world, but also with the academy and government. They have to know the markets trends and regulatory developments, where consumer needs are going, and where technological and business model opportunities lie. Some of those may be prevalent in Brazil, in which case the challenge for Brazilian companies is simplified. However, creating a global impact requires an awareness of what is going on outside of Brazil.

Brazilians can travel to the Silicon Valley and Silicon Valley participants can travel to Brazil. A first step in bridging the gap between academia and the corporate world and between the Silicon Valley and Brazil was the First Silicon Valley Institute for Business Innovation Un-conference (SViBi) that took place in Mountain View, California, in January 2017. Academics from the University of California Berkeley, Stanford University, Harvard University, the London Business School, and the University of Chicago, amongst others, met with a broad range of Brazilian companies and other international firms, from the sectors of healthcare, aviation, banking, and cosmetics to discuss how to foster innovation-friendly ecosystems in Brazil.

It is very important to connect across boundaries, organizational and geographic, to find ideas from the outside; from Silicon Valley, Cambridge, Milan, Shanghai, TelAviv, and Geneva. There are bits and pieces of a new future scattered everywhere. Indeed, one of the key attributes of the Silicon Valley is that it is itself connected to other entrepreneurial hubs. As a result of this, whatever one does in Brazil, one is necessarily connected to other key ecosystems beyond Silicon Valley.

These ecosystems are found around the world and also in Latin America. While building and maintaining these links might be an exhausting job, it must be done. Not doing so would imply a possible lapse and a risk of using outmoded technology. Embarking on such an endeavor is challenging and a parochial mindset would not be conducive. However, those who venture out and augment their firms' dynamic capabilities will herald the progress of their local communities and their country.

\section{REFERENCES}

Augier, M., \& Teece, D. J. (2009). Dynamic capabilities and the role of managers in business strategy and economic performance. Organization Science, 20(2), 410421. doi:10.1287/orsc.1090.0424

Chandler, A. (1990). Scale and scope: The dynamics of industrial capitalism. London, UK: Harvard Business School Press.

Somaya, D., Teece, D. J., \& Wakeman, S. (2011). Innovation in multi-invention contexts: Mapping solutions to technological and intellectual property complexity. California Management Review, 53(4), 47-79. doi:10.1525/cmr.2011.53.4.47

Teece, D. J. (2010). Business models, business strategy and innovation. Long Range Planning, 43(2-3), 172-194. doi:10.1016/j. Irp.2009.07.003

Teece, D. J., Peteraf, M., \& Leih, S. (2016). Dynamic capabilities and organizational Aagility. California Management Review, 58(4), 13-35. doi:10.1525/cmr.2016.58.4.13

Teece, D. J., Pisano, G., \& Shuen, A. (1997). Dynamic capabilities and strategic management. Strategic Management Journal, 18(7), 509-533. doi: 10.1002/ (sici)1097-0266(199708)18:7く509::aid-smj882>3.0.c0;2-z 